Eixo Temático: Desenvolvimento de Estratégias Didáticas

\title{
ET-07-009 \\ DAMA QUÍMICA: UMA FORMA LÚDICA E INTERATIVA PARA LIGAÇÕES IÔNICAS E COVALENTES NO 9 ANO
}

Lindaura Laís Silva Santos ${ }^{1,4}$, Deise Machado ${ }^{1,4}$, Maria José Dias Sales ${ }^{2,4}$, Eltamara Souza da Conceição $0^{3,4}$

${ }^{1}$ Bolsistas do Programa Institucional de Bolsas de Iniciação a Docência.

${ }^{2}$ Professora regente.

${ }^{3}$ Coordenadora de Área.

${ }^{4}$ Universidade do Estado da Bahia. Departamento de Ciências Exatas e da Terra II - Campus II. Rod. Alagoinhas-Salvador, Km 03, Zona Rural, Alagoinhas-BA (CEP 48000-000).

http://dx.doi.org/10.21472/congrebio2016.et-07-009

\section{RESUMO}

Foi feita a aplicação de uma atividade lúdica na Escola Estadual dos Rodoviários, utilizando de novas abordagens metodológicas para facilitar o ensino-aprendizagem do educando. A atividade aplicada foi em forma de jogo: Dama Química, abordando conteúdo de química, ligações iônicas e covalentes. Durante a aplicação da atividade notou-senos alunos empolgação e interação, uma participação ativa e uma satisfatória relação professor-aluno, possibilitando uma troca de conhecimentos de forma dinâmica.

Palavras-chave: Ensino-Aprendizagem; Química; PIBID.

\section{INTRODUÇÃO}

A Química como ciência da natureza está em nosso cotidiano, seja pela presença de substâncias naturais ou antropogênicas, sendoportanto sempre presente em nossasvidas,e fundamental para a nossa sobrevivência entendê-la. Os conteúdos relacionados a esta ciência tornam-se complexos para o aprendizado dos educando, mesmo sabendo dessa relação com a sua vida, devido ao caráter abstrato que possui.

O ensino de Química nas escolas encontra grandes problemas, começando pelo baixo número de docentes que lecionam a disciplina ser de fato licenciado na área. Além disso, muitas vezes, o método trabalhadopelos educadores em sala de aula não instiga a curiosidade e atenção do educando, e por isso os mesmos não conseguem entender a relevância dos conceitos discutidos, não conseguem transpor a sala de aula e contextualizar os conteúdos. O método de ensino de modo geral, se restringindo somenteao uso de livros, lousa, repetindo apenas os exemplos do livro didático e sem recurso laboratorial, dificultando o aprendizado. Ainda é incipiente o numero de educadores que explora de fato as experimentações, em especial, a ludicidade no ensino de Química. Corroborando com esta afirmação:

O ensino da química seria bem mais simples e agradável se fossem abandonadas as metodologias ultrapassadas muito utilizadas no ensino tradicional, isto é, os métodos onde os únicos recursos didáticos utilizados pelo professor para repassar os conteúdos aos alunos são o quadro, o pincel e a linguagem oral e se investissem mais nos procedimentos didáticos alternativos (BERNARDELLI, 2004). 
Grande parte dos educandos demonstra não ter afinidade com Química, e o índice de reprovação nesta área é significativo. Sendo assim, é notória a urgência de inovar a partir de métodos inovadores e que provoque o interesse e o gosto dos educandos pelos conteúdos. Segundo Vygotsky (1989), o lúdico influencia enormemente o desenvolvimento da criança. É através do jogo que esta aprende a agir, sua curiosidade é estimulada, que adquire iniciativa e autoconfiança. Este ainda proporciona o desenvolvimento da linguagem, do pensamento e da concentração. Daí a relevância da utilização de jogos, músicas, atividades experimentais para o aprendizado. Sobretudo para despertá-los e sensibilizá-los para o quanto dependemos dos processos químicos para nossa existência, como ela se apresenta de formas variadas. Segundo Freire (1996) "ensinar não é transferir conhecimento, mas criar as possibilidades para a sua própria produção ou a sua construção”.

A utilização de um jogo didático em Química tem por fim incentivar o amplo conhecimento das representações que se tem no componente, sobretudo quando se almeja desenvolver no discente a capacidade de reconhecer as definições químicas, tais como: nomenclaturas dos elementos químicos, tabela periódica, átomo, misturas homogêneas e heterogêneas, fórmulas, entre outros conteúdos químicos.Contudo é evidente e essencial aplicar variadas opções de metodologias, tais como jogos, vídeos e paródias,para forma qualificar as aulas, estimular a interação dos educandos com o docente, permitindo ampla participação do educando, sobretudo ouvindo suas opiniões, de forma a dinamizar a aula. Isso é fundamental para o entendimento da importância da química na vida desses educandos. Almeida (1998) afirma que é preciso reencontrar caminhos novos para a prática pedagógica escolar, uma espécie de libertação, de desafios, uma luz na escuridão, assim, a educação lúdica pode ser uma boa alternativa.

O material lúdico-pedagógico não deve ser visto apenas como um jogo,que os alunos usam para brincar, mas como uma atividade onde se aprende com diversão e dever propor o desenvolvimento social, ético e moral do discente. Como menciona Schwartz (2004), o lúdico é uma filosofia pedagógica, uma forma de sentir o ensino-aprendizagem, não é somente um método ou uma técnica de ensino. Então, as atividades lúdicas precisam ganhar espaço na metodologia escolar, quebrando as restrições tradicionais, fazendo do aluno não mais um expectador do processo educativo, mas um agente participativo, ativo, peça fundamental da construção de seus conhecimentos.

De acordo com Melo (2005) o lúdico é um importante instrumento de trabalho e para o professor, uma possibilidade de oferta de forma de construção do conhecimento, respeitando as diversas singularidades. Essas atividades, quando bem exploradas, oportunizam a interlocução de saberes, a socialização e o desenvolvimento pessoal, social e cognitivo.

Campos (1986) afirma que a ludicidade pode ser uma ponte facilitadora da aprendizagem, desde que o professor possa pensar e questionar sobre sua forma de ensinar, relacionando a utilização do lúdico como fator motivador de qualquer tipo de aula. Pois, o professor que utiliza as práticas lúdicas envolve o educando em pontos essenciais e o leva a gostar dos conteúdos ministrados, buscando o conhecimento, sem ser pressionado.

\section{OBJETIVO}

O objetivo do trabalho é desenvolver e realizar a utilização de um jogo didáticopedagógico para abordagem do assunto ligações iônicas e covalentes, no Ensino Fundamental II, do Colégio Estadual dos Rodoviários, em Alagoinhas-BA.

\section{METODOLOGIA}

Na confecção do jogo, foi necessário distribuir um composto iônico e covalente, aleatoriamente, para cada quadrado da dama em branco. Mas, para o sucesso e desenvolvimento apropriado do jogo, foi fundamental colocar dois compostos (um iônico e um covalente) no mesmo quadrado branco da dama, repetindo em mais três quadrados diferentes (Figura 1). As 
regras elaboradas foram às seguintes: 1. Só poderia mover as peças, se as ligações fossem iguais; 2. Quando ganhar a pedra do adversário, poderia trocar de ligação; 3. A pedra que chegasse ao quadrado com duplo composto, poderia escolher qual ligação seguir, se iônica ou covalente.

Os recursos utilizados foram: papelão; tabela periódica impressa; folhas duplaface; cola; tabuleiro comum de dama impresso com modificações baseadas nos compostos iônicos e covalentes; regras para ordenar o posicionamento dos jogadores, diante de situações dúbias; e pedras de dama.

O jogo da "Dama Química” foi aplicadona turma do $9^{\circ}$ ano, por bolsistas do Programa Institucional de Bolsas de Iniciação a Docência - PIBID, auxiliado pela docente regente da área de Ciências da escola.

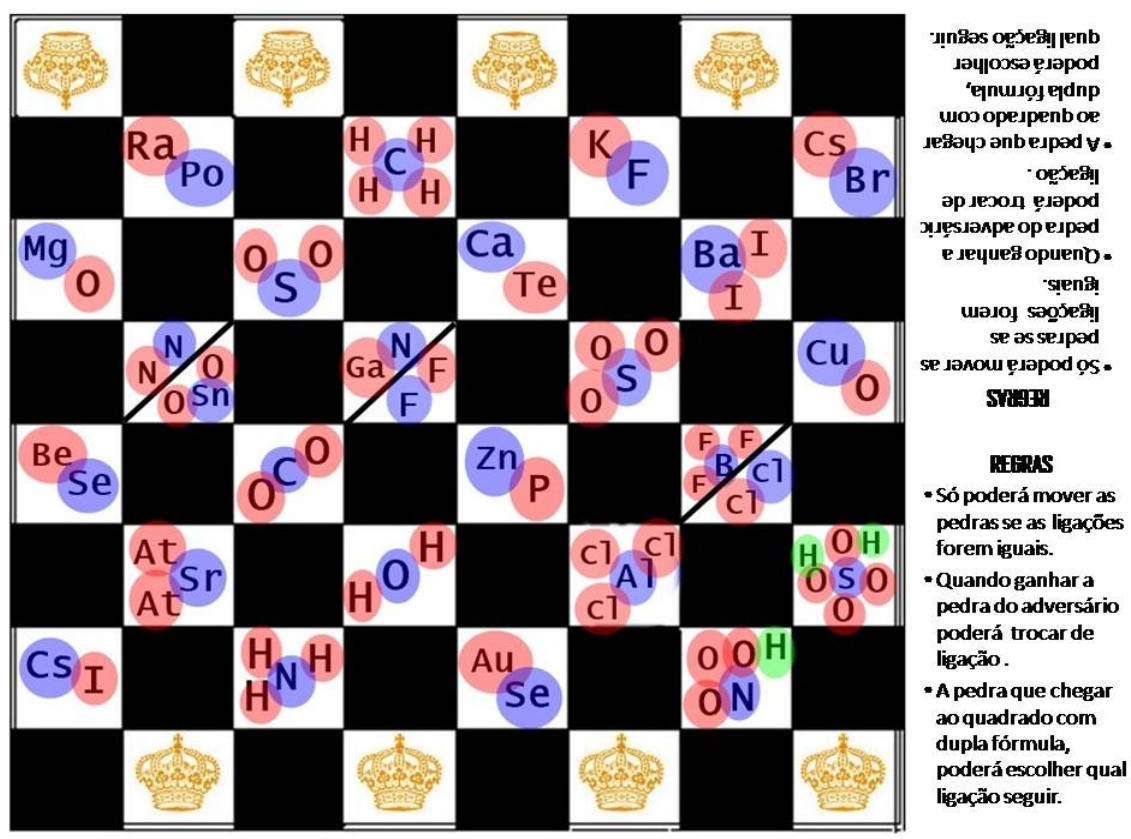

Figura 1. Representação do Jogo Dama Química. Fonte: Arquivo Pessoal.

Para aplicá-lo, foi necessário dividir a turma em várias duplas. Sendo que o objetivo do exercício foitornar os discentes capazes de identificar e diferenciar uma ligação iônica de uma covalente. Desse modo, ao traçar adequadas estratégias para ganhar as pedras do adversário, consequentemente, o estudante vencia o jogo.

\section{RESULTADOS E DISCUSSÃO}

Antes da aplicação do jogo, os educandos encontravam-se inquietos, ansiosos e curiosos para saber como iria ser. De início, estavam receosos em não saber resolver, mas mantiveram o espírito de competitividade, mesmo apresentando uma pequena resistência. Com o auxílio da docente e das bolsistas, foram gradativamente vencendo o medo e a atividade ocorreu tranquilamente. Com o tempo, já estavam "independentes” sabendo como agir, refletindo diante dos desafios propostos, e não mais erravam ou infligiam as regras do jogo. Utilizavam a tabela periódica, que tinha por finalidade diminuir as chances de erro entre uma ligação iônica ou covalente. No final da atividade foi notória a satisfação de todos na sala, especialmente, da 
docente em ver que os educandos conseguiram realizar a atividade com sucesso, comprovando que aprenderam o assunto de uma forma divertida, cumprindo com os objetivos da atividade.

Enfim, observou-se que cada dupla de educandos demonstrava tranquilidade e concentração para interagir uns com os outros. Sendo o interesse pelo jogo notórioe a competição, o efeito que despertou o interesse maior pelo conteúdo trabalhado. Sendo a relação entre os bolsistas e professora regente com os educandos facilitada pelo trabalho desenvolvido.

A utilização de jogos adaptados ou criação de novos jogos para os conteúdos da sala de aula é importante na formação do discente, pois segundo Friedmann (1996), a cognição e o desenvolvimento intelectual são exercitados em jogos onde o educando possa testar principalmente a relação causa-efeito. Na vida real isto geralmente é impedido pelos adultos, normalmente para evitar alguns desastres e acidentes. Entretanto, no jogo,esteseducandos podem vivenciar estas situações e testar as mais variadas possibilidades de ações. Suas ações interferem claramente no resultado do jogo. Então é necessário que passe a realizar um planejamento de estratégias para vencer o jogo. No caso do jogo individual, pode testar as possibilidades e vontades próprias e relacioná-las com as conseqüências e resultados. No ensino de Química é relevante a utilização de jogos, porque muitas vezes, há deficiência nas escolas para manutenção de laboratórios bem equipados, a ponto de fornecer segurança suficiente para a manipulação de produtos químicos, os quais podem gerar acidentes.

Negrine (1998) afirma que as atividades prazerosas atuam no organismo causando sensação de liberdade e espontaneidade. Portanto, facilita aprendizagem por sua própria acepção, pois os mecanismos para os processos de descoberta são intensificados com a utilização das atividades lúdicas. Assim pôde-se perceber durante a aplicação do jogo "Dama Química”, em que se observou interesse e prazer nos educando em participar da atividade, sobretudo porque, ao sondá-los informalmente sobre o conteúdo posteriormente, percebeu-se que aprenderam satisfatoriamente.

O jogo proposto cumpriu seu objetivo, tanto divertindo os educandos como permitindo a construção do conhecimento por estes. Soareset al. (2004) indica que a atividade lúdica pode ser definidacomo uma ação divertida, seja qual for o contexto linguístico, desconsiderando o objeto envolto na ação, e se há regras, pode ser considerada um jogo. $\mathrm{O}$ jogo mostra duas funções: a lúdica e a educativa (Kishimoto, 1996); se a lúdica prevalecena atividade, não passa de um jogo, já se a educativapredomina é apenas um material didático. Portanto, é fundamental a existências das duas, havendo equilíbrio para desenvolvimento eficaz. Com as atividades lúdicas cumprimos os mesmos objetivos que uma aula tradicional, na qual tem por recursos apenas o livro didático e a lousa, só que de uma maneira mais leve para os estudantes. Sendo essencial que no espaço escolar, se utilize novas alternativas de ensino.

O jogo é um método adequado, pois é uma atividade que mexe com o emocional e o intelectual do educando, incentivando-o a pensar em estratégias para resolver as situações propostas pelo exercício, assim buscando um bom desempenho em relação à resolução dos problemas. Assim, o uso deste jogo na turma em questão foi também essencial para o bom desempenho dos educandos, resultando na ampla aprovação dos educandos na disciplina. Segundo Melo (2005), a diversidade de estudos a respeito das atividades lúdicas atestam que o jogo, além de ser fonte de prazer e descoberta para o educando, traduz o cenário sócio-histórico, refletido na cultura, possibilitando a contribuição significativa no processo de construção do conhecimento do educando como mediador de aprendizagem.A atividade lúdica, sobretudo o jogo, evidencia um bom resultado porque estimula ao educando refletir, questionar se a sua ação trará benefícios em relação ao jogo, levando-o a pensar sobre o assunto estudado e assim aprender, sem precisar memorizar.

De acordo com os PCN's (1999), o Ensino de Química “deve possibilitar ao aluno a compreensão, tanto de processos químicos em si, quanto da construção de um conhecimento científico em estreita relação com as aplicações tecnológicas e suas implicações ambientais, sociais, políticas e econômicas”. O conhecimento da Química deve ser um meio de interpretar o mundo e intervir na realidade, além de desenvolver capacidades como interpretação e análise de dados, argumentação, conclusão, avaliação e tomadas de decisões (CASTILHO et al., 1999; 
PCN’s, 1999). Assim a aplicação de atividades lúdicas, vem a ser uma ferramenta que dá um suporte relevante para se alcançar esses objetivos.

A atividade lúdica também atende aos quesitos propostos pelos PCN's, pois possibilita que o educando tenha compreensão dos processos químicos estudado na escola, visualizando as devidas aplicações no seu cotidiano. Proença (2002) afirma que os jogos oferecem um contato simulado com a realidade modelada, permitindo um espaço de vivência e apreciação de experimento e reflexão. A maneira lúdica do jogo é o diferencial dos outros pressupostos usados como modelo, por exemplo, leitura e estudo, já que o jogo propicia uma dinamização do conteúdo estudado em sala. Assim, o jogo quanto a sua dinâmica lúdica precisa ser considerado como método pedagógico relevante, pois busca atingir a qualidade na metodologia aplicadaao educando para sua aprendizagem.

Em suma, pode-se concluir que a ludicidade não leva a memorização do assunto explicado, mas permite ao educando pensar, refletir e raciocinar. Além disso, as práticas favorecem para o desenvolvimento linear ouprogresso das competências e habilidades, elevando a motivação dos educandos perante as aulas de Química, já que o lúdico integra várias dimensões do educando, como afeto, trabalho em equipe, lidar com regras e limitações, promovendo a construção do conhecimento cognitivo, físico e social.

\section{CONSIDERAÇÕES FINAIS}

A utilização do Jogo Dama Química foi uma estratégia pedagógica altamente relevante para tornar dinâmica a aplicação do conteúdo, facilitando o aprendizado do educando. A atividade lúdica propiciou um ambiente mais favorável e estimulante para o desenvolvimento intelectual e criativo dos educandos, tornando o conteúdo mais acessível e significativo.

Além disso, possibilitou a ampliação, tantos pelos pibidianos, quanto pela professora regente, de experiências bem sucedidas sobre o uso de métodos pedagógicos dinâmicos. Essa experiência para os pibidianos, ajudou a enxergar suas potencialidades sobre o desenvolvimento de suas capacidades pessoais e profissionais, os encorajando a novos desafios em adaptações de novos jogos. Enquanto docentes em formação, vivências com esta nos permitiram buscar formas de execução do nosso trabalho, que de fato motive e envolva os educandos numa aula mais divertida e produtiva.

\section{AGRADECIMENTOS}

Agradecemos a CAPES por conceder bolsa de ID e de Coordenação de Área. À Universidade do Estado da Bahia, pela oportunidade e a Escola Estadual dos Rodoviários, que permitiu e colheu os pibidianos.

\section{REFERÊNCIAS}

ALMEIDA, P. N. Educação lúdica: Técnicas e jogos pedagógicos. 9 ed. rev. e ampl. São Paulo: Loyola, 1998.

BERNARDELLI, M. S. Encantar para ensinar - um procedimento alternativo para o ensino da Química. In: CONVENÇÃO BRASIL LATINO AMÉRICA, CONGRESSO BRASILEIRO E ENCONTRO PARANAENSE DE PSICOTERAPIAS CORPORAIS. Foz do Iguaçu. Anais... 2004. Centro Reichiano, 2004.

BRASIL. Secretaria de Educação Média e Tecnologia, Ministério da Educação. Parâmetros Curriculares Nacionais do Ensino Médio. Brasília, 1999.

CAMPOS, D. M. S. Psicologia da aprendizagem. 19 ed. Petrópolis: Vozes, 1986. 
FREIRE, P. Pedagogia da Autonomia. Saberes necessários à prática educativa. São Paulo: Paz e Terra, 1996.

FRIEDMANN, A. O direito de brincar: a brinquedoteca. 4. ed. São Paulo: Abrinq, 1996.

KISHIMOTO, T. M. (Org.). Jogo, brinquedo, brincadeira e a educação. 5 ed. São Paulo: Cortez, 2001.

MELO, C. M. R. As atividades lúdicas são fundamentais para subsidiar o processo de construção do conhecimento. Información Filosófica, v. 2, n. 1, p. 128-137, 2005.

NEGRINE, A. Terapias corporais: a formação pessoal do adulto. Porto Alegre: Edita, 1998.

PROENÇA, D. J. Critérios e experiências no uso de jogos pedagógicos. Brasília: Redes, 2002.

SCHWARTZ, G. M. (Org.). Dinâmica lúdica, novos olhares. Barueri: Manole, 2004.

SOARES, M. H. F. B.; OKUMURA, F.; CAVALHEIRO, E. T. G. Proposta de um jogo didático para ensinar o conceito de equilíbrio químico. Química Nova na Escola, n. 18, p. 13, 2003.

VYGOTSKY, L. S. A formação social da mente. 6. ed. São Paulo: Martins Fontes, 1998. 